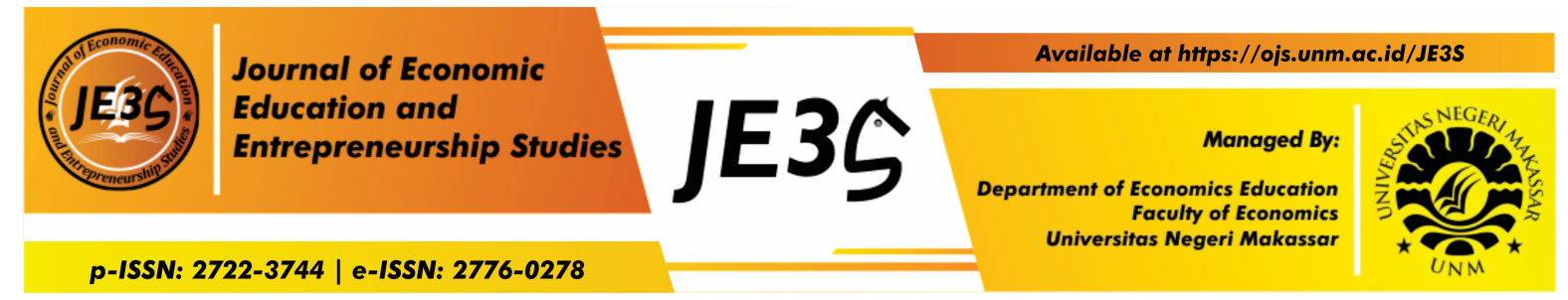

\title{
Pengembangan Metode ISAKE Social Research Design
}

Dedy Febry Rachman ${ }^{1 *}$, Syaiful Amri ${ }^{2}$

${ }^{1,2}$ Universitas Bumigora

\section{Article History}

Received May 15, 2020

Approved June 18, 2020

Published June 30, 2020

\begin{tabular}{l}
\hline Keywords \\
\hline Development, Method, ISAKE \\
\hline JEL Classification \\
\hline I21, D83 \\
\hline
\end{tabular}

\begin{tabular}{l}
\hline How to Cite \\
\hline Rachman, D. F., \& Amri, S. 2020. \\
Pengembangan Metode ISAKE Social \\
Research Design. Journal of Economic \\
Education and Entrepreneurship Studies, \\
1(1), 31-38.
\end{tabular}

\footnotetext{
* Dedy Febry Rachman

Jl. Ismail Marzuki No. 22, Cilinaya, Universitas Bumigora

Kota Mataram, Propinsi NTB, Negara Indonesia, Kode Pos 83127

e-mail: dedyfebry18@gmail.com
}

\begin{abstract}
The purpose of this research development is expected to produce a product of social research methods: 1). Learning devices, 2). Learning assessment/ evaluation guidelines, 3). Product social research methods, based on the identification of learning objectives.
\end{abstract}

Based test results, social research methods are very valid, interesting, and effective can be applied in classroom learning. This can be seen from the results of small group product trials found $87 \%$ results and class trials were carried out after going through stages that were feasible to be applied in a classroom learning. The results of the pretest and posttest tests were found to be satisfactory with a value of $100 \%$, which indicates that this product was able to boost students' interest and learning outcomes, in this case, using the development product in the form of ISAKE social research methods in social research design materials.

This method can also be used for a wider audience with adjustments, especially adjustments to the characteristics of students as users. Furthermor, ISAKE's social research methods that have been developed and can be integrated with the use of renewable information and communication technology 
instansi pendidikan desa ataupun kota. Penyelidikan sosial merupakan bagian yang tidak terpisahkan dari kerja membangkitkan kesadaran, menggerakkan dan mengorganisasikan siswa. Penyelidikan sosial merupakan sebuah upaya yang sungguh-sungguh dan serius untuk meneliti keadaan siswa dan keadaan masyarakat pada umumnya, sehingga kita dapat memahami dan mengerti tentang persoalanpersoalan yang dihadapi oleh siswa, sebab-sebabnya dan pendekatan apa yang digunakan untuk menyelesaikan persoalan tersebut.

Prinsip penting dalam penyelidikan sosial bahwa tujuan penyelidikan sosial bukan semata-mata untuk mengetahui sehingga mampu menerangkan situasi yang ada, tapi lebih penting dari itu adalah merubah keadaan atau situasi tersebut menjadi lebih baik. Karena mampu menerangkan situasi adalah penting, tetapi lebih penting lagi adalah mengubahnya. Jadi penyelidikan sosial merupakan pekerjaan aktif untuk mengubah dunia menjadi lebih baik.

Dewasa ini, penyelidikan sosial juga merupakan sebuah cara untuk tidak bekerja secara serampangan, asal-asalan atau sembarangan. Banyak orang malas untuk melakukan penyelidikan sosial, malas untuk meneliti secara mendalam kondisi di mana ia hidup, bekerja dan bertempat tinggal. Banyak orang juga berkata bahwa hanya dengan membaca buku, koran atau merenung di rumah, maka mereka akan mengerti tentang situasi konkret masyarakat. Adalah tidak benar bahwa tanpa melangkahkan kaki ke luar pintu rumah, maka kita dapat mengerti dan memahami banyak hal. Yang akan terjadi kemudian justru apa yang ada dalam pikiran kita yang kita anggap sebagai kebenaran dan kenyataan dan bukannya kenyataan dan kebenaran itu sendiri yang ada di luar diri kita, di tengah massa rakyat. Itu adalah kesalahan berpikir dan kesalahan di dalam memahami kenyataan dan situasi konkret.

Adapun tahapan sederhana dari penelitian sosial ISAKE ini adalah: 1). Persiapan dalam merancang penelitian sosial 2). Merancang penelitian sosial 3). Melakukan penelitian sosial sederhana 4). Mengumpulkan data 5). Mengolah data dan publish. Dengan demikian, peserta didik akan dilatih untuk mampu membaca, memahami serta menafsirkan permasalahan sosial ekonomi yang ada di sekitarnya, terutama berkaitan dengan metode penelitian sosial. Metode penelitian sosial dalam proses pembelajaran khusus untuk ilmu sosial ekonomi masih jarang ditemukan dalam proses belajar-mengajar. Harusnya di era digital sekarang membuat pengajar mampu mendapatkan akses tanpa batas dalam mencari literasi untuk menciptakan strategi dan metode yang bersifat inovatif dan menarik dalam proses pembelajaran di kelas. Oleh karena itu, perlu adanya pengembangan sebuah metode penelitian dalam pembelajaran yang sifatnya khusus untuk mata pelajaran sosial dan ekonomi untuk meningkatkan minat belajar ekonomi. Sejauh mana siswa mengetahui dan memahami beberapa materi, konsep-konsep ekonomi dan peningkatan kemampuan/skill dalam merancang dan melakukan penelitian sosial.

\section{METODE}

Secara keseluruhan, metode penelitian pengembangan yang digunakan dalam penelitian ini adalah Research and Development atau yang biasa disebut dengan (R\&D). Metode penelitian yang digunakan dalam penelitian ini adalah metode pengembangan. Metode pengembangan dirancang dengan menggunakan acuan pada desain pengembangan Borg dan Gall. Menurut Borg dan Gall (1989), "educational research and development is a process used to develop and validate educational 
product'. Metode penelitian dan pengembangan juga didefinisikan sebagai suatu metode penelitian yang digunakan untuk menghasilkan produk tertentu dan menguji keefektivitasan produk tersebut.

Menurut Borg dan Gall, pendekatan research and development (R\&D) meliputi sepuluh tahapan mulai dari (1) research and information collecting; (2) planning; (3) develop preliminary form of product; (4) preliminary field testing; (5) main product revision; (6) mainfield testing; (7) operational productrevision; (8) operational field testing; (9) final product revision; (10) dissemination and implementation.

Ada dua jenis data yang dikumpulkan dalam pengembangan Metode Pembelajara. Jenis data yang pertama adalah data yang diperlukan untuk merevisi produk Metode Pembelajaran yang bersumber dari Ahli Materi Ekonomi/isi dan ahli media, guru dan siswa melalui uji coba lapangan. Data yang dihimpun mengenai kualitas Metode Pembelajaran, kemenarikan, serta keterterapan materi di dalam Metode Pembelajaran. Jenis data yang kedua, yaitu data yang berkaitan dengan proses dan hasil belajar melalui uji lapangan. Data yang dihimpun untuk mengetahui keefektifan Metode Pembelajaran yang dikembangkan. Data tersebut diperoleh dari nilai hasil belajar siswa melalui kegiatan individu dan kelompok, lembar observasi aktivitas siswa non tes.

Untuk memperoleh sejumlah data yang diharapkan, digunakan instrumen pengumpul data. Jabaran aspek yang dinilai, instrumen yang digunakan, data yang diamati dan responden yang terlibat dapat dilihat pada Tabel 1.

Tabel 1. Instrumen Data yang Diamati dan Responden

\begin{tabular}{ccccc}
\hline Tujuan & $\begin{array}{c}\text { Aspek yang } \\
\text { Dinilai }\end{array}$ & Instrumen & $\begin{array}{c}\text { Data yang } \\
\text { Diamati }\end{array}$ & Responden \\
\hline $\begin{array}{c}\text { Kelayakan } \\
\text { produk Metode } \\
\text { Pembelajaran } \\
\begin{array}{c}\text { Group } \\
\text { Investigation }\end{array}\end{array}$ & $\begin{array}{c}\text { Validitas } \\
\text { produk }\end{array}$ & $\begin{array}{c}\text { Lembar } \\
\text { validasi }\end{array}$ & $\begin{array}{c}\text { Kevalidan } \\
\text { Metode } \\
\text { Pembelajaran }\end{array}$ & $\begin{array}{c}\text { Ahli Materi } \\
\text { Ekonomi/isi }\end{array}$ \\
\cline { 2 - 5 } $\begin{array}{c}\text { Kocial Analysis } \\
\text { Class }\end{array}$ & $\begin{array}{c}\text { Keefektifan } \\
\text { produk }\end{array}$ & $\begin{array}{c}\text { Lembar } \\
\text { penilaian }\end{array}$ & $\begin{array}{c}\text { Hasil belajar } \\
\text { siswa }\end{array}$ & Siswa \\
\cline { 4 - 5 } & $\begin{array}{c}\text { Aktivitas } \\
\text { belajar siswa }\end{array}$ & Observer (guru) \\
\hline
\end{tabular}

Sumber: Olah data, 2020

Teknik analisis data yang akan digunakan dalam pengembangan Metode Pembelajaran ini adalah 1). Analisis Deskriptif Kualitatif. Analisis ini digunakan untuk menganalisa data berupa catatan, saran atau komentar berdasarkan lembar penilaian yang terdapat pada lembar validasi, lembar observasi dan angket tanggapan guru dan siswa. 2). Analisis Deskriptif Kuantitatif yang digunakan untuk menganalisis data berupa skor/angka-angka dari hasil lembar validasi, lembar observasi dan angket. 


\section{HASIL DAN DISKUSI}

Data pada penelitian dan pengembangan metode pembelajaran ISAKE secara berurutan adalah tanggapan ahli isi/materi ekonomi, uji kelompok kecil dan uji coba lapangan. Data hasil uji coba dipaparkan sebagai berikut:

\section{Uji Validasi Ahli Isi/Materi}

Uji ahli isi/materi diperlukan sebagai evaluator terhadap isi/materi yang sudah dikembangkan oleh peneliti. Data yang diperoleh berupa data kuantitatif dan kualitatif melalui lembar validasi yang diberikan peneliti kepada ahli isi/materi. Dari angket yang diberikan kepada validator ahli materi yang berisikan 20 butir pertanyaan dan kolom essay maka didapatkan hasil yang cukup memuaskan sebesar $90 \%$ valid dan layak untuk di uji cobakan, atas hasil perolehan tersebut jika di konversi yang berarti nilai 100 (sempurna). Selanjutnya hasil tersebut dikonversikan pada tingkat kevalidan produk sebagaimana kriteria yang di kutip dari pendapat (Sugiyono, 2017:147) maka hasil tersebut mendapat kriteria sangat valid.

\section{Uji Kelompok Kecil}

Uji coba kelompok kecil. Subjek uji coba sebanyak lima orang siswa kelas XI MAN 2 Mataram. Kelima orang tersebut terdiri dari dua orang siswa berkemampuan baik, dua orang siswa berkemampuan sedang dan satu orang siswa berkemampuan rendah. Tujuan uji coba perorangan adalah untuk mengetahui kemenarikan produk metode pembelajaran ISAKE. Proses uji coba berlangsung selama kurang lebih 60 menit setelah jam istirahat dan peneliti tetap berada di sekitar siswa agar dapat membimbing dalam melakukan penilaian agar mendapatkan hasil seperti yang diharapkan. Hasil uji coba kelompok kecil pada Tabel 2.

Tabel 2. Hasil Uji Coba Kelompok Kecil

\begin{tabular}{|c|c|c|c|c|c|c|}
\hline \multirow{2}{*}{ No } & \multirow{2}{*}{ Aspek yang dinilai } & \multicolumn{5}{|c|}{ Skor Perolehan Siswa Ke- } \\
\hline & & 1 & 2 & 3 & 4 & 5 \\
\hline 1 & $\begin{array}{l}\text { Apakah petunjuk penggunaan metode } \\
\text { pembelajaran ini bisa kalian pahami }\end{array}$ & 4 & 4 & 3 & 4 & 4 \\
\hline 2 & $\begin{array}{l}\text { Apakah petunjuk bagian-bagian pada } \\
\text { metode pembelajaran membantu kalian } \\
\text { dalam belajar menggunakan metode } \\
\text { pembelajaran }\end{array}$ & 3 & 3 & 3 & 4 & 3 \\
\hline 3 & $\begin{array}{l}\text { Apakah isi materi jelas dan bisa kalian } \\
\text { pahami }\end{array}$ & 4 & 4 & 4 & 4 & 4 \\
\hline 4 & $\begin{array}{l}\text { Apakah tampilan metode pembelajaran } \\
\text { yang ada pada metode pembelajaran bisa } \\
\text { membantu kalian dalam belajar }\end{array}$ & 4 & 4 & 4 & 4 & 4 \\
\hline 5 & $\begin{array}{l}\text { Apakah kalian bisa memahami bahasa } \\
\text { yang ada pada metode pembelajaran }\end{array}$ & 4 & 4 & 3 & 4 & 3 \\
\hline 6 & $\begin{array}{l}\text { Apakah soal-soal yang terdapat pada } \\
\text { metode pembelajaran berhubungan dengan } \\
\text { masalah kehidupan sehari hari yang bisa } \\
\text { kalain mengerti }\end{array}$ & 4 & 4 & 4 & 4 & 4 \\
\hline
\end{tabular}




\begin{tabular}{|c|c|c|c|c|c|c|}
\hline \multirow{2}{*}{ No } & \multirow{2}{*}{ Aspek yang dinilai } & \multicolumn{5}{|c|}{ Skor Perolehan Siswa Ke- } \\
\hline & & 1 & 2 & 3 & 4 & 5 \\
\hline 7 & $\begin{array}{l}\text { Apakah kegiatan belajar yang terdapat } \\
\text { dalam metode pembelajaran bisa } \\
\text { membantu kalian memahami materi } \\
\text { rancangan penelitian sosial }\end{array}$ & 3 & 4 & 4 & 4 & 4 \\
\hline 8 & $\begin{array}{l}\text { Apakah kalian bisa mengerjakan tugas } \\
\text { sesuai dengan metode tersebut }\end{array}$ & 2 & 4 & 4 & 4 & 3 \\
\hline 9 & $\begin{array}{l}\text { Apakah kalian bisa membuat kesimpulan } \\
\text { penelitian dari metode ISAKE }\end{array}$ & 3 & 4 & 2 & 3 & 2 \\
\hline 10 & $\begin{array}{l}\text { Apakah kalian bisa mengerjakan soal pada } \\
\text { evaluasi hasil belajar dan angket }\end{array}$ & 2 & 4 & 4 & 4 & 2 \\
\hline & Jumlah Skor Perolehan & 33 & 39 & 35 & 39 & 33 \\
\hline & Persentase Skor (\%) & 82,5 & 97,5 & 87,0 & 97,5 & 82,5 \\
\hline & Rata-rata & & & $87 \%$ & & \\
\hline
\end{tabular}

Sumber: Olah data, 2020

Berdasarkan Tabel 2, perolehan rata-rata dari uji coba kelompok kecil sebesar 87\%. Setelah dikonversi persentase tersebut termasuk dalam kategori sangat menarik. Beberapa catatan berupa komentar dan saran yang dirangkum dari lembar angket kemenarikan disajikan pada Tabel 3.

Tabel 3. Komentar dan Saran

\begin{tabular}{cl}
\hline No. & Saran dan Komentar \\
\hline 1. & Tingkatkan lagi \\
2. & Saya tertangtang untuk mencobanya \\
3. & Sangat jelas dan ringkas
\end{tabular}

Sumber: Hasil Olah Data, 2020

Adanya Saran dan komentar dari hasil uji coba kelompok kecil ini selanjutnya dijadikan bahan untuk merevisi produk sebelum melanjutkan kepada uji coba lapangan.

\section{Uji Coba Lapangan}

Uji coba lapangan dilakukan dengan melibatkan 34 orang siswa kelas XI (unggulan) MAN 2 Mataram. Uji coba lapangan dilakukan dengan dua cara yaitu proses Pre-test (sebelum menggunakan produk) dan Pos-test (setelah menggunakan prouk metode pembelajaran) uji ini dilakukan untuk mengetahui perbedaan tingkat hasil belajar siswa dalam menggunakan metode ISAKE yang sudah di kembangkan. Hasil belajar siswa diambil dari penilaian pada proses pembelajaran siswa di kelas sebelum dan sesudah menggunakan produk metode pembelajaran ISAKE pada materi rancangan penelitian sosial. 
Pretest Hasil Belajar Siswa

Persentase Hasil Belajar Siswa Pretest sebelum menggunakan metode pembelajaran ISAKE ini tergambar pada tabel hasil belajar siswa.

Tabel 4. Pretest Hasil Belajar Siswa

\begin{tabular}{cccccc}
\hline & & & \multicolumn{2}{c}{ Kriteria } \\
\cline { 4 - 6 } No. & Rentang Nilai & Frekuensi & Persentase & Tuntas & Tidak Tuntas \\
\hline 1. & $50-60$ & 14 & 41.22 & & 14 \\
2. & $60-70$ & 13 & 38.20 & & 13 \\
3. & $70-80$ & 7 & 20.58 & 7 & \\
4. & $80-90$ & & & & $\mathbf{2 7}$ \\
5. & $90-100$ & & & $\mathbf{7}$ & $\mathbf{7 9 . 4 \%}$ \\
\hline Jumlah & 34 & $\mathbf{1 0 0 \%}$ & $\mathbf{2 0 . 6 \%}$ & \\
\hline Prosentase & & &
\end{tabular}

Sumber: Hasil Olah Data, 2020

Hasil belajar sebelum menggunakan metode pembelajaran ISAKE dengan materi pembahasan rancangan penelitian social menunjukkan bahwa hasil belajar sebelum menggunakan metode pembelajaran adalah sebanyak 27 siswa atau 79,4\% mengalami tidak tuntas dalam proses pembelajaran, dan hanya 7 orang siswa saja yang mengalami tuntas belajar atau sebesar 20,6\% dari total 34 siswa yang mengikuti proses pembelajaran di kelas XI (unggulan).

\section{Postest Hasil Belajar Siswa}

Dalam hasil belajar setelah menggunakan metode pembelajaran ISAKE menunjukkan bahwa hasil belajar adalah sebanyak 13 orang siswa berada pada rentang nilai hasil belajar di atas $80-90$ atau $38,5 \%$ dan di anggap tuntas dalam proses pembelajaran kategori memuaskan, sedangkan dari rentang nilai 90-100 sebanyak 21 orang siswa tuntas dalam proses pembelajaran setelah menggunakan metode pembelajaran dengan nilai yang sangat memuaskan atau sebesar $61,5 \%$ dari total 34 siswa yang mengikuti proses pembelajaran di kelas XI (unggulan) MAN 2 Mataram. 
Tabel 5. Postest Hasil Belajar Siswa

\begin{tabular}{lcccc}
\hline \multirow{2}{*}{ No. } & Rentang Nilai & Frekuensi & Persentase & \multicolumn{2}{c}{ Kriteria } \\
\cline { 4 - 5 } & & & Tuntas & Tidak Tuntas \\
\hline 1. & $50-60$ & & & \\
2. & $60-70$ & & & \\
3. & $70-80$ & & & 13 \\
4. & $80-90$ & 13 & 38.5 & 21 \\
5. & $90-100$ & 21 & 61.5 & 34 \\
\hline Jumlah & & 34 & & $\mathbf{1 0 0 \%}$ \\
\hline Prosentase & & $\mathbf{1 0 0 \%}$ & \\
\hline
\end{tabular}

Sumber: Hasil Olah Data, 2020

Dari pemaparan hasil belajar setelah menggunakan metode ISAKE di atas menunjukkan tabel distribusi hasil belajar siswa diatas menunjukkan bahwa siswa mencapai ketuntasan belajar terbanyak dicapai dengan rentang skor 90-100 dengan persentase sebesar 61,5\%. Peringkat ketuntasan kedua dicapai oleh siswa pada rentang skor 80-90 dengan persentase sebesar 38,5\%. Ini menunjukkan bahwa produk metode pembelajaran ISAKE dengan materi rancangan penelitian sosial yang dikembangkan dapat meningkatkan hasil belajar pada siswa kelas XI (unggulan) MAN 2 Mataram.

\section{KESIMPULAN}

1. Hasil validasi ahli materi menunjukkan metode pembelajaran ISAKE (group investigation social analysis Class) ini layak diterapkan.

2. Dari hasil angket yang diberikan kepada siswa dan guru bahwa produk metode pembelajaran ISAKE ini mendapat apresiasi yang baik.

3. Dan Dari Hasil uji coba lapangan yang telah dilakukan kepada siswa kelas XI (unggulan) MAN 2 Mataram menunjukkan bahwa produk metode pembelajaran sangat efektif digunakan pada materi rancangan penelitian sosial.

\section{DAFTAR PUSTAKA}

Borg. W.R, dan Gall, M.D. 1989. Educational Research: An Introductio, New York Longman.

Budiati, A, C. 2018. Sosiologi Kontekstual Untuk SMA \& MA, Surakarta - CV Mediatama 
Budiawati, E, 2014, Peningkatan Hasil Belajar IPS Menggunakan Metode Pembelajaran Protofolio Pada Siswa Kelas VI SDN Nglarang Mlati Sleman. Universitas Negeri Yogyakarta.

Dedy, F,R 2018, Pengembangan Model Pembelajaran MTMA, Vol 2, No 2 (2018): JPEK - E-Journal Hamzanwadi.

Desminta, 2005, Psikologi Perkembangan, Bandung - PT. Remaja Rosdakarya.

Muhaimin, 2009. Modul Wawasan Pengembangan Model pembelajaran bab VMalang: LKP2-I

Niswatul, 2014, Pengembangan bahan ajar IPA berbasis inkuiri untuk kelas V SD, EJournal, Universitas Negeri Malang

Rusman, 2012, Metode-metode Pembelajaran mengembangkan profesionalisme guru, Jakarta - PT. Raja Grafindo Persada.

Sugiyono, 2011, Statistika untuk Penelitian, Bandung - CV Alfabeta.

Sugiyono, 2017, Metode Penelitian Kuantitatif, Kualitatif dan R\&D. Bandung: PT Alfabet.

Thobroni, Muhammad \& Arif Mustofa. 2011. Belajar \& Pembelajaran: Pengembangan Wacana dan Praktik Pembelajaran dalam Pembangunan Nasional. Jogjakarta: Ar-Ruzz Media. Tahun-2003-Sisdiknas.pdf), diakses 7 september 2019.

Trianto. 2007. Model-model Pembelajaran Inovatif. Jakarta: Grasindo

Wahyono, Hari, 2013, Revitalisasi Pendidikan Ekonomi, Perilaku Berkarakter dan Permasalahan Ekonomi. Malang: Materi seminar pendidikan nasional 